\title{
A Plant Arabinogalactan-Like Glycoprotein Promotes a Novel Type of Polar Surface Attachment by Rhizobium leguminosarum
}

\author{
Fang Xie, Alan Williams, Anne Edwards, and J. Allan Downie \\ John Innes Centre, Norwich Research Park, Norwich NR4 7UH, U.K. \\ Submitted 12 August 2011. Accepted 3 October 2011.
}

\begin{abstract}
Rhizobium leguminosarum bv. viciae can attach to the roots of legume and non-legume plants. We wanted to determine whether root exudates could affect in vitro surface attachment in a confocal microscopy assay. Root exudate from pea, other legumes, wheat, and Arabidopsis induced $R$. leguminosarum bv. viciae to attach end-on (in a polar manner) to glass in hexagonal close-packed arrays, rather than attaching along their long axis. This did not involve a reorientation but was probably due to altered growth. The polar attachment involves a novel bacterial component because it occurred in mutants lacking a symbiosis plasmid (and hence nodulation genes) and polar glucomannan. The major surface (acidic) exopolysaccharide was required, and mutations affecting exported proteins and flagella delayed but did not block polar attachment. The polar attachment activity was purified as a high molecular weight fraction from pea root exudate and is an arabinogalactan protein (AGP) based on its carbohydrate content, reactivity with AGP-specific monoclonal antibodies and Yariv reagent, and sensitivity to enzymes that degrade proteins and carbohydrates. We propose that this novel mode of AGPinduced attachment may be important for growth of these bacteria on the roots of both legumes and non-legumes.
\end{abstract}

During the initiation of the symbioses that occur between legumes and rhizobia, the bacteria attach near the tips of growing root hairs (Fujishige et al. 2006, 2008; Laus et al. 2006). In this location, the rhizobia can grow using exudates from the roots; it also enables the bacteria to optimize their chances of infecting legume roots using the molecular dialogue that is required to initiate the infections that lead to the nitrogen-fixing symbiosis. The attached bacteria can catabolize a wide range of root exudate metabolites (Knee et al. 2001) and, in response to secreted flavonoids, produce nodulation lipo-chito-oligosaccharide signaling molecules (nodulation [Nod] factors) which induce the changes in root and root hair development required for infection and nodule development (Downie 2010). However, very few of the rhizobia in soil will succeed in infecting root nodules and therefore, like other rhizosphere bacteria (Danhorn and Fuqua 2007), they must have alternative growth strategies. Rhizobia attach to legume roots and root hairs and

F. Xie and A. Williams contributed equally to this work.

Current address for A. Williams: Dept of Medical Microbiology, Royal Free Hospital, Pond Street, London NW3 2QG, U.K.

Corresponding author: J. Allan Downie; Telephone: +(44) 1953 887728; E-mail: allan.downie@jic.ac.uk grow to form stable biofilms, both around the tips of root hairs and along the cell-cell junctions on the root epidermis (Fujishige et al. 2006; Matthysse and Kijne 1998; Williams et al. 2008). This attachment can be assisted by the plant; for example, a pea lectin promotes the attachment of Rhizobium leguminosarum bv. viciae to the root hair tip (Laus et al. 2006) by binding to the unipolarly located glucomannan exopolysaccharide (EPS) (Laus et al. 2006), without which root hair attachment and root infection are greatly reduced (Williams et al. 2008). There is a similar mode of attachment by agrobacteria, which are phylogenetically very similar (Tomlinson and Fuqua 2009). There are other means of root attachment of R. leguminosarum bv. viciae involving the major surface EPS (Laus et al. 2005; Russo et al. 2006; Williams et al. 2008), extracellular adhesins such as Rhizobium attachment proteins (RAP) that bind to the EPS (Ausmees et al. 2001; Russo et al. 2006), and a protein called rhicadehesin that promotes aggregation on root hairs (Smit et al. 1992). Nod factor production activated by plant-made flavonoids can significantly stimulate the formation of structured biofilm formed in vitro (Fujishige et al. 2006, 2008), implying a role in attachment to legume root hairs. Several root-exudate components in addition to flavonoids can also affect molecular communication in the rhizosphere (Faure et al. 2009; Gao et al. 2003; Keshavan et al. 2005; Mark et al. 2005; Matilla et al. 2007).

There are clearly nutritional advantages to bacteria that are attached to plant roots (Danhorn and Fuqua 2007; Estabrook and Yoder 1998) and rhizobia can also attach to and form biofilms on roots and root hairs of non-legumes (Santaella et al. 2008). In this study, we analyzed the effects of root exudates on biofilm formation by $R$. leguminosarum and showed that a high molecular weight root-exudate glycoprotein can dramatically alter the mode of attachment of the bacteria in vitro. This occurs via activation of novel mechanism of bacterial attachment that can occur in mutants lacking nod genes and is different from the polar attachment mediated by the glucomannan EPS.

\section{RESULTS}

Root exudate induces growth

of $\boldsymbol{R}$. leguminosarum in polar arrays on glass.

In static culture, $R$. leguminosarum bv. viciae formed in vitro biofilms made up of an interconnected network separated by voids. These were initiated by individual cells binding to the glass and then attaching laterally forming long chains of cells lying side by side on the glass (Fig. 1A); layers of bacteria then attached to these surface-attached cells (Russo et al. 2006; Williams et al. 2008). Sterile root exudate from axenically grown pea seedlings caused $R$. leguminosarum bv. viciae to 
attach to the glass in what looks like hexagonal close-packed arrays, with their poles attached to the glass (Fig. 1B), in contrast to the long chains of laterally interacting cells observed (Fig. 1A) after growth in the absence of root exudate (Fig. 1C and D illustrate the optical sections used). Additional layers forming the biofilm in the presence of root exudate were similar to those formed in the absence of root exudate.

To determine whether added pea root exudate could induce a reorientation of bacteria already attached laterally to the glass, root exudate was added to a developing biofilm (36 h after inoculation) after the pattern of lateral attachment of some cells had already been established. The subsequent changes in attachment were then monitored every $4 \mathrm{~h}$; no change in orientation was observed with those bacteria that were already laterally attached. However, cells attaching to the glass after the addition of the root exudate did so in a polar manner (Fig. 1E, circled). resulting in some bacteria being attached side-on and some end-on. To test whether the root exudate altered the surface characteristics of the glass, we pretreated the glass surface with root exudate for $30 \mathrm{~min}$, removed the liquid, then added fresh medium and assayed biofilm formation; in such experiments, no arrays of polar attached bacteria were seen (Fig. 1F).
Pea root exudate contains nod-gene-inducing flavonoids, which alter biofilms of shaken cultures (Fujishige et al. 2008), but no change in attachment or biofilm formation was observed following the addition of the flavonoids naringenin (Fig. 1G), eriodictyol, or apigenin (data not shown) at $1 \mu \mathrm{M}$. Several other metabolites in pea root exudate (Harborne and Baxter 1999) were tested but no induction of polar attachment was seen with glucose, galactose, arabinose, rhamnose, mannose, serine, glycine, glutamic acid, proline, or homoserine (data not shown).

Root exudates from Medicago truncatula, Lotus japonicus, wheat, and Arabidopsis thaliana all induced polar attachment (Fig. 1H, I, and J for root exudates from M. truncatula, wheat, and A. thaliana), showing that the induced polar attachment is not specific to Rhizobium sp.-legume interactions.

\section{Requirements for surface polar attachment} by $R$. leguminosarum bv. viciae.

To determine whether genes required for polar attachment were on the symbiosis plasmid, we compared the effects of root exudate on strain A34 (carrying the symbiosis plasmid pRL1JI) and the related strain 8401, which lacks a symbiosis
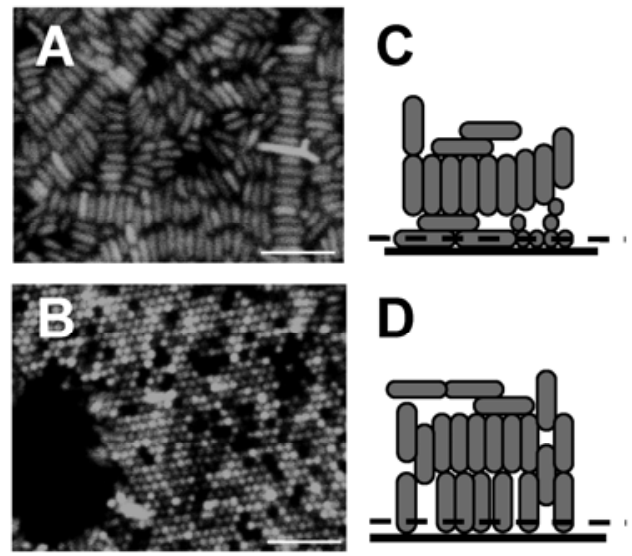
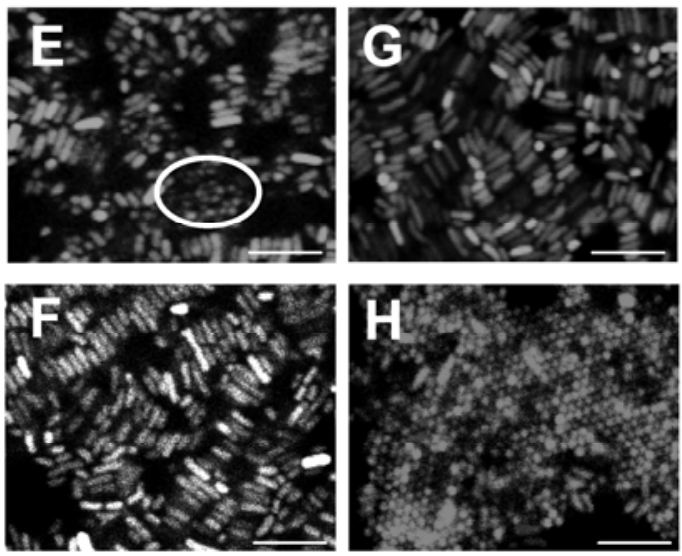
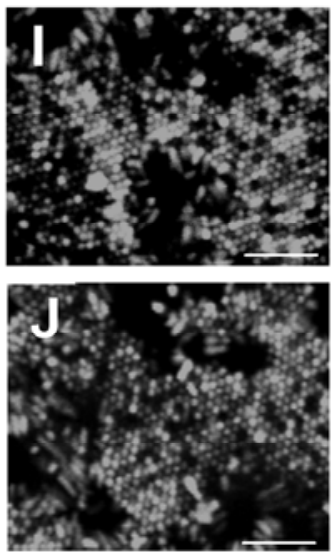

Fig. 1. Root-exudate-induced end-on (polar) attachment of Rhizobium leguminosarum bv. viciae to glass. R. leguminosarum bv. viciae 3841 expressing green fluorescent protein on pHC60 was grown for 3 days in minimal medium in glass-bottomed chambers and attachment to the glass surface was monitored by confocal microscopy as described previously (Russo et al. 2006; Williams et al. 2008). A, No addition. B, Pea root exudate was added. C and D, Diagrams showing that, in A and B, only those cells adjacent to the glass were imaged. The broken line shows the optical section and the full line represents the glass to which the bacteria attach. E, Pea root exudate was added $36 \mathrm{~h}$ after inoculation; the oval shows polar cells which attached after the addition of root exudate. F, The chamber was pretreated with root exudate for $30 \mathrm{~min}$ and then the root exudate was removed before inoculation. $\mathbf{G}$, Naringenin was added at $1 \mu \mathrm{M}$. H, Root exudate from Medicago truncatula was added. I, Wheat root exudate was added. J, Arabidopsis thaliana root exudate was added. Bars correspond to $5 \mu$ m.
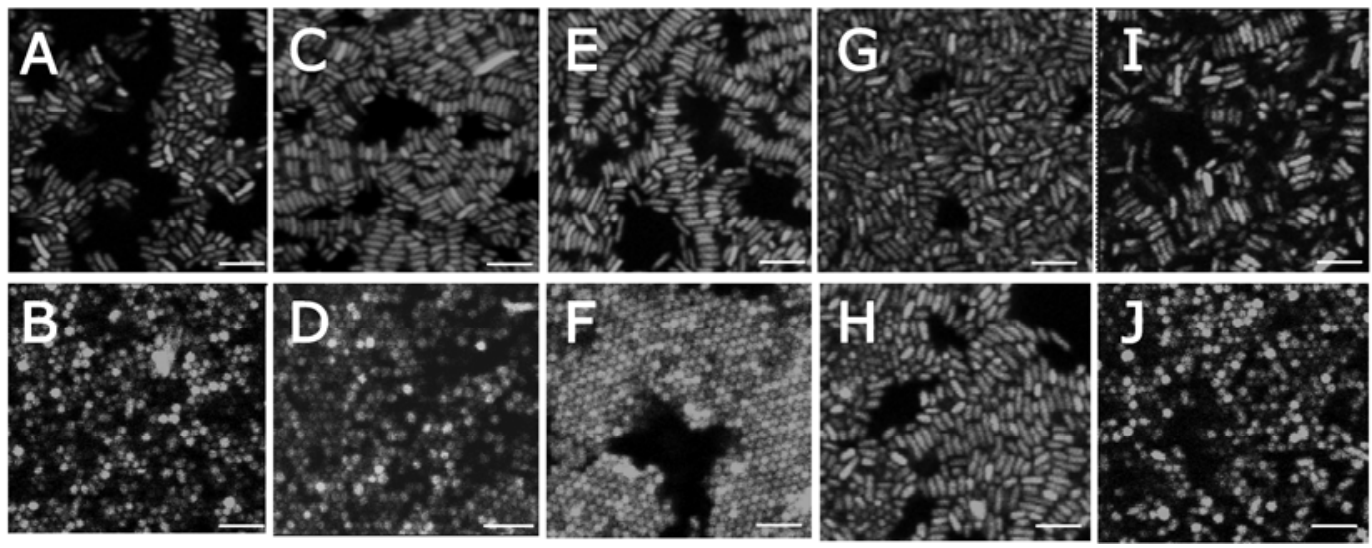

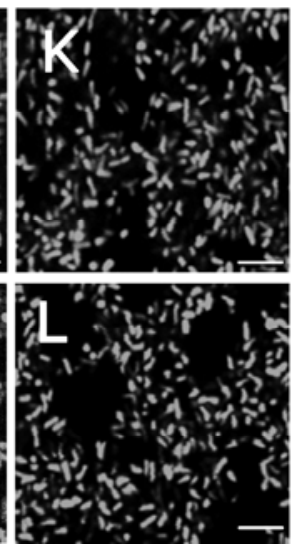

Fig. 2. Induction of polar attachment of Rhizobium leguminosarum bv. viciae is Sym plasmid independent and is blocked at pH 7.5 and by mutation of pssA. Strains were grown for 3 days in minimal medium, monitoring attachment to the glass bottoms of growth chambers by confocal microscopy as described previously (Russo et al. 2006; Williams et al. 2008). Upper images are all with bacteria grown with minimal medium and the bottom images are all with bacteria grown with added root exudate. A and B, Strain A34. C and D, Strain 8401 (lacking a Sym plasmid). E and F, Strain 3841 with the pH of the growth medium adjusted to $\mathrm{pH6.5}$. G and $\mathbf{H}$, Strain 3841 with the $\mathrm{pH}$ of the growth medium adjusted to $\mathrm{pH} 7.5$. I and $\mathbf{J}$, Strain A1045 (gmsA). K and L, Strain A1073, (pssA). All strains carried pHC60. Bars correspond to $5 \mu \mathrm{m}$. 
plasmid. Both showed root-exudate-induced polar attachment (Fig. 2A to D), ruling out a role for the symbiosis plasmidborne nod and rhi (rhizosphere-expressed) genes in the induced polar attachment.

Attachment to root hairs mediated by the extracellular protein rhicadhesin occurs even in the absence of the symbiosis plasmid (Smit et al. 1989). The gene encoding rhicadhesin has not been identified and, therefore, a genetic test was not possible. Rhicadhesin-mediated attachment occurs at $\mathrm{pH} 7.5$ but is essentially absent at pH 6.5 (Smit et al. 1986; Laus et al. 2006). We tested the effect of $\mathrm{pH}$ on attachment by using buffered $\mathrm{Y}$ medium. Root exudate induced polar attachment at $\mathrm{pH} 6.5$ but it was mostly absent at $\mathrm{pH} 7.5$ (Fig. 2E to $\mathrm{H}$ ), excluding a role for rhicadhesin. The chains of surface-attached bacteria formed in the absence of root exudate were greatly reduced at $\mathrm{pH} 7.5$ (Fig. $2 \mathrm{G})$, suggesting that the higher $\mathrm{pH}$ may affect surface interactions that lead to the formation of these chains of bacteria.

The polar-located glucomannan was not required for rootexudate-induced polar attachment because mutation of glucomannan synthase ( $g m s A$ ) had no effect (Fig. 2I and J). Mutations in genes required for other extracellular polysaccharides, including cellulose (A1060, celA), gel-forming polysaccharide (A1090, gelA), and in an exoY-like gene (A1020) that encodes an EPS synthesis-like gene (Williams et al. 2008) did not affect polar attachment (Fig. 3A to C). Strain A1073 (pssA) lacking the acidic EPS essential for nodule infection did not show root-exudate-induced polar attachment (Fig. $2 \mathrm{~K}$ and L). However, as seen previously (Williams et al. 2008), this strain did not produce normal structured biofilms or arrays of horizontally attached bacteria in chains on the glass surface and, therefore, it is possible that the absence of EPS affects the ability to establish normal cell-cell interactions.

Several predicted adhesins, including the polar RAP (Ausmees et al. 2001), are secreted by $R$. leguminosarum bv. viciae via the prsD-prsE-encoded type I secretion system (Krehenbrink and Downie 2008); we tested whether such proteins were required by using strain A912 carrying mutations in all three type I secretion systems. Strain A912 showed a somewhat abnormal biofilm in minimal medium, with a less well formed three-dimensional structure; the induction of polar attachment by root exudate was delayed but not blocked (Fig. 3D), showing that proteins (including the adhesins) secreted via these exporters are not essential for the polar attachment.
$R$. leguminosarum bv. viciae 3841 has three predicted autotransporters (Krehenbrink and Downie 2008) but a triple autotransporter mutant (A1019) was normal for polar attachment (Fig. 3E). There is also a type VI protein secretion system homologous to the imp genes described previously (Bladergroen et al. 2003); mutation of the impL orthologue pRL120464, encoding an essential component of this secretion system, delayed and reduced but did not block induction of polar attachment (Fig. 3F). Instead of being visible 2 to 3 days after inoculation, polar attachment was not seen until 4 to 5 days after inoculation and, even then, only approximately 40 to $70 \%$ of the bacteria attached end on.

$R$. leguminosarum bv. viciae 3841 has a cluster of genes homologous to the Agrobacterium tumefaciens vir genes that encode a pilus (Krehenbrink and Downie 2008). However, mutation of the virB6 homologue (pRL70154), which would be predicted to be required for pilus formation (Jakubowski et al. 2003), did not affect in vitro biofilm formation or the root-exudate-induced polar attachment (Fig. 3G). Caulobacter crescentus has a pilus that induces polar attachment, and the cpa gene encoding a protein required for pilus assembly is conserved in R. leguminosarum bv. viciae (Krehenbrink and Downie 2008); however, mutation in the gene homologous to cpaB (RL0213) had no effect on root-exudate-induced polar attachment in vitro (Fig. 3H).

We observed that mutations affecting regulators (Tambalo et al. 2010b) of motility and chemotaxis (Rem, VisN, and VisR), FliF (the MS ring protein required for flagellar assembly) (Chevance and Hughes, 2008), the flagellar hook protein FlgE, and deletion of both chemotaxis clusters che1 and che 2 (Miller et al. 2007) strongly affected the formation of chains of interacting bacteria attached on the surface after growth in minimal medium (Fig. 4A, C, E, G, and I). Similar results were seen with the che1 deletion mutant but the che2 deletion (Miller et al. 2007) had no effect on surface attachment (data not shown).

We then tested the effects of the various motility mutations on root-exudate-induced polar attachment. In the $f l i F, f l g E$, che1/che 2 double (Fig. 4F, $\mathrm{H}$, and $\mathrm{J}$ ), and che1 (data not shown) mutants, polar attachment was delayed (usually by approximately 2 days) and was somewhat variable but clearly present. There was no delay with the visRrem (Fig. 4B and D) and visN (data not shown) mutants. The abnormal attachment observed in the absence of root exudate was not simply due to
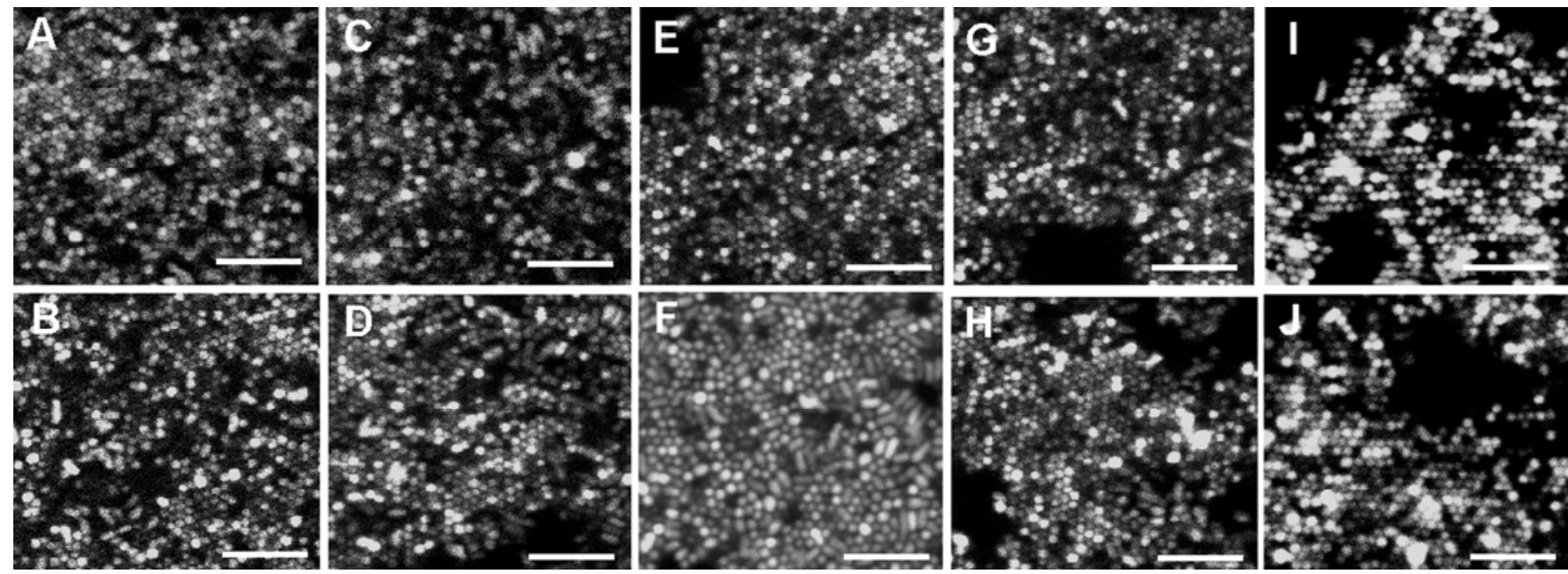

Fig. 3. Assays of polar attachment with various mutants affecting extracellular components in Rhizobium leguminosarum bv. viciae 3841. Assays were done using the following mutants: A, A1060 (celA); B, A1020 (exoY); C, A1090 (gelA); D, A912 (prsD toaD, tobD); E, A1019 (autA, autB, autC); F, A1319 (impL; type VI secretion); G, A897 (virB6); H, A1056 (cpaB); I, 3841 motA; J, 3841 motB- Attachment to the glass bottoms of growth chambers was monitored as described previously (Russo et al. 2006; Williams et al. 2008), except that, in D and F, the polar attachment was only observed in bacteria grown for 5 rather than 3 days. Bars correspond to $5 \mu \mathrm{m}$. 
a loss of motility, because mutations in flaA and flaB did not strongly affect the mode of attachment in minimal medium (data not shown) even though these mutants are nonmotile (Tambalo et al. 2010a). These two mutants were normal for root-exudate-induced polar attachment (data not shown).

Taking together these observations with mutants, we conclude that we have identified a previously unrecognized mode of bacterial attachment that is induced by a plant-made component in root exudate.

\section{Purification of the plant root-exudate factor inducing polar surface attachment.}

Heat treatment $\left(100^{\circ} \mathrm{C}\right.$ for $\left.10 \mathrm{~min}\right)$ of the root exudate had no effect on its activity (Fig. 5D). Treatment with the proteases PronaseE or ProteinaseK followed by heat inactivation of the proteases abolished induction of polar attachment (Fig. 5A and B). Similarly, treatment of the root exudate with an enzyme preparation (ViscozymeL) that degrades carbohydrates also abolished the induction of polar attachment by root exudate (Fig. 5C). These treatments suggested that the activity might be due to a glycoprotein released by plant roots.

We established that the active component bound to anion and reverse-phase columns but not to a cation-exchange resin. To purify the active component, root exudate was passed through a weak cation-exchange column and then a DEAESephadex column, eluting the activity with $0.3 \mathrm{M} \mathrm{NaCl}$. This fraction was then loaded onto a $\mathrm{C} 18$ reverse-phase column, and the activity was eluted with $30 \%$ methanol in water. The eluted sample was then concentrated and applied to a Superdex200 FPLC (fast protein liquid chromatography) gel filtration column. The active fraction from this column eluted just after the exclusion volume with an apparent size of approximately $300 \mathrm{kDa}$, well separated from most other compounds detected by absorbance (Fig. 6A).

We were surprised at the apparent high molecular weight of the active fraction and, therefore, used spin columns to test whether lower molecular weight components in crude root exudate had any activity. No activity came through filters with molecular weight cut-offs of 3,000, 10,000, and 30,000. The observation that all the activity was in the high molecular weight complex separated by column chromatography suggests some sort of aggregate or multimeric component.
Characterization of the polar-attachment factor from pea root exudate.

Carbohydrate analysis revealed (Table 1) that the purified component was rich in arabinose and galactose and contained other sugars, including glucose and mannose, suggesting, that it contained an arabinogalactan protein (AGP). The absence of detectable galacturonic acid shows that the fraction is not significantly contaminated with pectin and the absence of detectable fucose and glucuronic acid indicates the absence of primary cell wall polymers such as xyloglucan and xylan. The
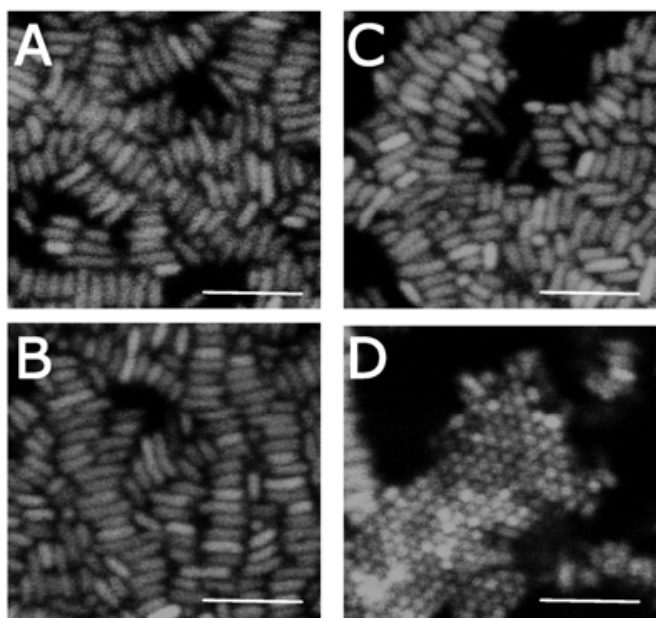

Fig. 5. Polar attachment is prevented by pretreatment of root exudate with protease or enzyme-degrading carbohydrates. Attachment of Rhizobium leguminosarum bv. viciae 3841 (containing pHC60) to the glass bottoms of growth chambers was monitored as described previously (Russo et al. 2006; Williams et al. 2008). Prior to addition to the assay, root exudate was incubated with proteases or ViscozymeL at $37^{\circ} \mathrm{C}$ and then heated at $75^{\circ} \mathrm{C}$ to inactivate the enzymes. A, Preincubation with pronase E. B, Preincubation with proteinase K. C, Preincubation with ViscozymeL. D, As a control for heat inactivation of enzyme activity, pronase $\mathrm{E}$ was heat treated as above and then incubated at $37^{\circ} \mathrm{C}$ with root exudate. The root exudate treated in this way retained polar attachment activity, showing that the inhibition of polar attachment was not due to active enzyme carried over to the polar attachment assay. Similar results were observed following heat treatment of proteinase $\mathrm{K}$ and ViscozymeL (data not shown). Bars correspond to $5 \mu \mathrm{m}$.
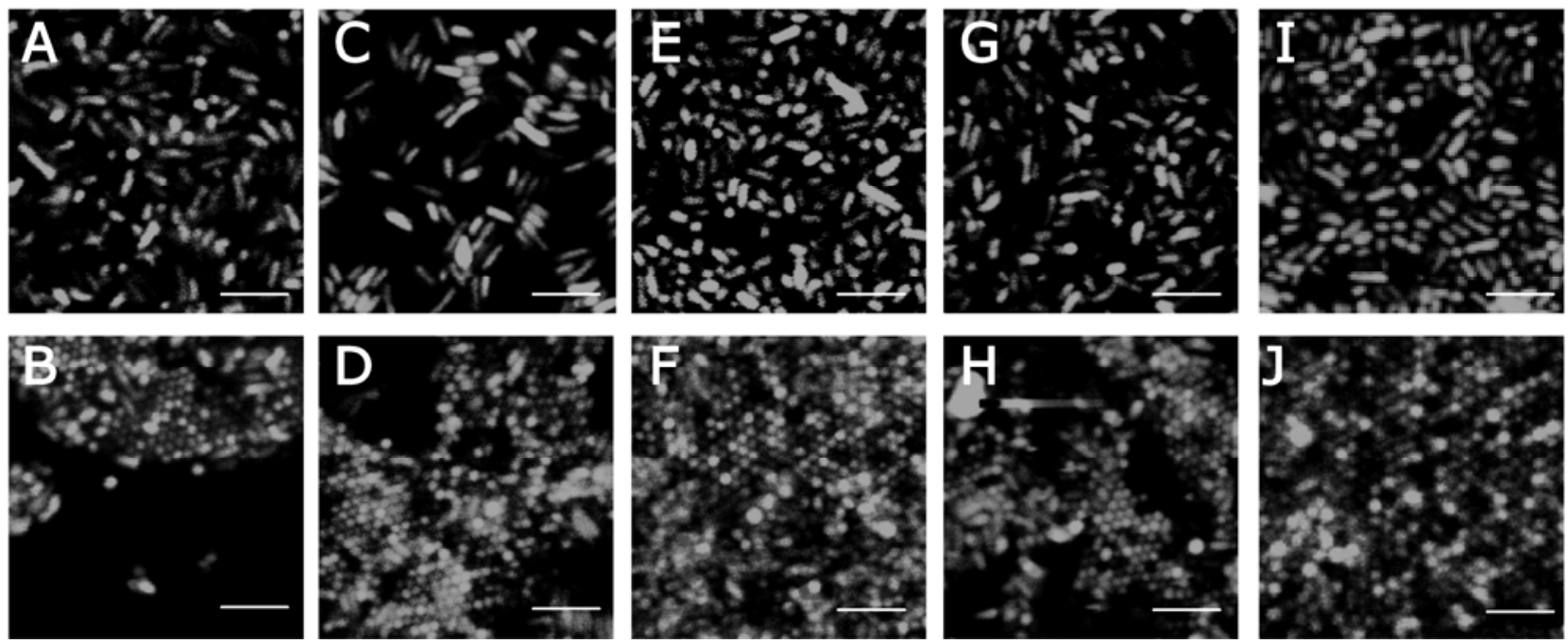

Fig. 4. Mutations in genes required for motility and flagella alter biofilm formation but do not block polar attachment. Induction of polar attachment in the absence (upper images) or presence (lower images) of pea root exudate. A and B, Strain 3841 visR $^{-}$. C and D, Strain $3841 \mathrm{rem}^{-}$. E and F, Strain A1414 (fliF).

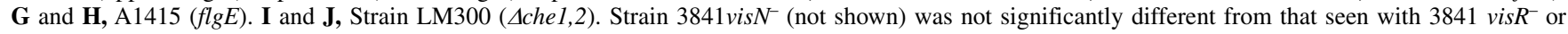
$3841 \mathrm{rem}^{-}$. Attachment to the glass bottoms of growth chambers was monitored as described previously (Russo et al. 2006; Williams et al. 2008) except that, in $\mathrm{F}, \mathrm{H}$, and $\mathrm{J}$, polar attachment was not consistently seen until 5 days of growth. All strains carried pHC60. Bars correspond to $5 \mu \mathrm{m}$. 
purified fraction was tested in a radial gel diffusion assay with Yariv reagent, which binds to AGP, producing a brown precipitate (Van Holst and Clarke 1985). The positive reaction indicated the presence of an AGP (Fig. 6B) and this was confirmed using the AGP-specific (Knox et al. 1991; Yates et al. 1996) monoclonal antibodies JIM13 (Fig. 6C) and LM2 (data not shown). These antibodies recognize epitopes on many AGP, whereas a different class of AGP, called an extensin-AGP secreted by pea root hairs, is recognized by the monoclonal antibody MAC265 (Rathbun et al. 2002); the MAC265 antibody did not react with the purified fraction (Fig. 6C), showing that the purified fraction is not simply a mixture of AGP exuded from roots.

The polar attachment activity from aseptically grown Arabidopsis thaliana seedlings fractionated and purified in exactly the same manner as described for pea root exudate. Although the final pattern of elution from the size fractionation column

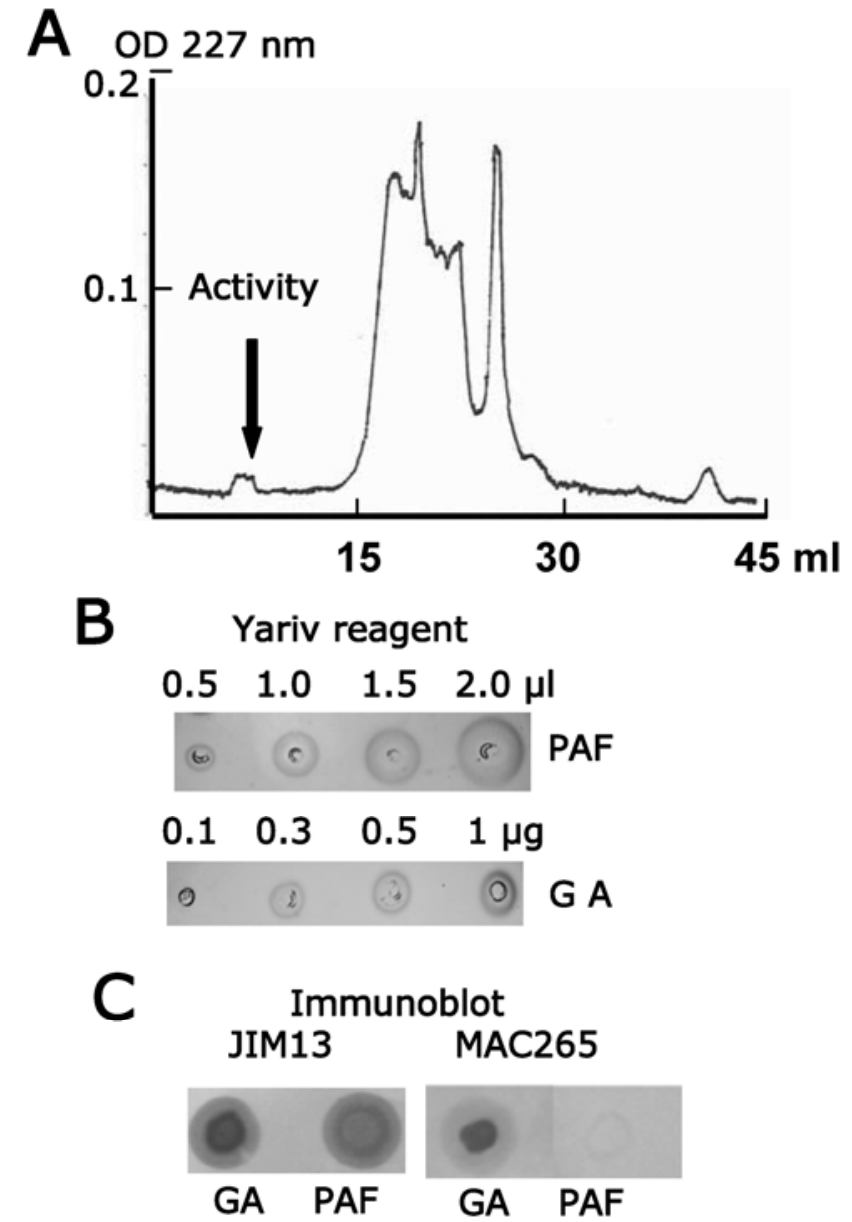

Fig. 6. Purification and assay of a pea root exudate fraction that induced polar attachment of Rhizobium leguminosarum bv. viciae. A, After cation exchange, DEAE Sephadex and reverse-phase column chromatography, a concentrated fraction containing the polar attachment activity was applied to a Superdex 200 Column and separated by FPLC, monitoring absorbance at $227 \mathrm{~nm}$. Only fractions 6, 7, and 8 induced polar attachment and these fractions were pooled and used for further assays. B, Aliquots of the purified polar attachment fraction (PAF) were pipetted into wells in an agarose gel containing Yariv reagent, which binds to arabinogalactan proteins. Gum arabic (GA) was used as a positive control. A positive reaction is seen as a ring diffusing from the well. $\mathbf{C}$, The purified polar attachment fraction $(1 \mu \mathrm{l})$ and GA $(1 \mu \mathrm{g})$ were blotted onto nitrocellulose and immunostained with the arabinogalactan protein (AGP)-specific rat monoclonal antibody JIM13 and the extensin AGP antibody MAC265 using anti-rat immunoglobulin $\mathrm{G}$ conjugated with alkaline phosphatase, and developed using 5-bromo-4-chloro-3-indolyl phosphate to detect the bound alkaline phosphatase. was somewhat different (data not shown), all the activity again eluted in the high molecular weight fraction.

\section{DISCUSSION}

We identified a high molecular weight root exudate fraction with the characteristics of an AGP; this caused R. leguminosarum bv. viciae to grow attached to the glass surface end on. This is different from the nod-gene-dependent altered attachment previously observed to be induced by flavonoids (Fujishige et al. 2008), because polar attachment was retained in a strain lacking nod genes. The in vitro polar attachment must be different from the lectin-glucomannan-mediated attachment to root hairs (Williams et al. 2008) because it occurred in the gmsA mutant that does not produce glucomannan. Polar attachment

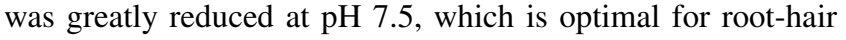
adhesion promoted by rhicadhesin (Swart et al. 1994), excluding a role for rhicadhesin. Therefore, this mode of attachment appears to be different from what has been described previously, and we believe that it could be important for attachment of rhizobia to roots of non-legumes and act in a complementary manner to the previously described legume-specific polar attachment mediated via specific lectins and glucomannan (Laus et al. 2006).

We could only visualize the root-exudate-induced polar attachment to glass by confocal microscopy; therefore, a highthroughput genetic screen to identify nonresponding mutants was not an option. Instead, we tested several mutants shown or predicted to be defective for protein export, production of surface polysaccharides, and surface structures such as pili and flagella. The only mutant completely defective for induction of polar attachment was the pssA mutant that lacks the major surface (acidic) EPS. This polysaccharide is required for polar attachment and this EPS is required for the production of biofilms in static culture (Russo et al. 2006; Williams et al. 2008); therefore, we cannot rule out the possibility that this EPS is required to maintain intimate interactions between cells in biofilms and, in the absence of this, close-packed arrays of polar attached bacteria cannot form.

Polar attachment was delayed but could still be induced in $f l g E$ and $f l i F$ mutants, which would be predicted to lack flagella but was normal in an flaA mutant which lacks a fully functional flagellar filament (Tambalo et al. 2010a). We conclude that, although flagella can promote polar attachment, they are not essential for it to occur. This is similar to what has been observed for agrobacterial polar attachment (Merritt et al. 2007), and these flagellar mutants have a small decrease in virulence (Chesnokova et al. 1997). We observed that mutations affecting, che1, rem, visR, visN, flgE, and fliF all affected attachment and biofilm formation in the absence of root exudate whereas the flaA mutation did not. Because the flaA mu-

Table 1. Sugar composition of purified polar attachment fraction

\begin{tabular}{lcc}
\hline Sugar & ${\text { Mass }(\mu \mathbf{g})^{\mathbf{a}}}$ & Mol $(\%)$ \\
\hline Arabinose & 26.4 & 46.5 \\
Rhamnose & 2.3 & 3.7 \\
Fucose & n.d. & $\ldots$ \\
Xylose & 2.2 & 3.9 \\
Glucuronic acid & n.d. & $\ldots$ \\
Galacturonic acid & n.d. & $\ldots$ \\
Mannose & 7.7 & 11.2 \\
Galactose & 17.1 & 25.1 \\
Glucose & 6.6 & 9.6 \\
$N$-acetyl galactosamine & n.d. & $\ldots$ \\
$N$-acetyl glucosamine & n.d. & $\ldots$ \\
$N$-acetyl mannosamine & n.d. & $\ldots$ \\
\hline
\end{tabular}

a Abbreviation: n.d. = not detected. 
tant is nonmotile, this implies that the difference is not simply caused by a lack of motility, implying that the che1, rem, visR, $v i s N$, flgE and fliF mutations may, in some way, cause an indirect regulatory defect. Delayed root-exudate-induced polar attachment was observed in the che $1, f l g E$, and $f l i F$ mutants but not the flaA, visN, visR, and rem mutants, again implying that the difference is not simply a lack of motility. These observations imply that there may be secondary regulatory effects of which we are unaware.

The type VI secretion system also appears to contribute to polar attachment by $R$. leguminosarum bv. viciae based on the observation that an impL mutant showed reduced and delayed polar attachment. This secretion system plays a role in attachment of pathogenic bacteria to animal cells and in biofilm formation (Aschtgen et al. 2010), although a role for the type VI secretion system in attachment to plants has not been described. The observed reduction and delay in attachment could be due to an effect of a secreted component or possibly even due directly to absence of components of the secretion system, which extends across the outer membrane (Schwarz et al. 2010).

The most likely way that such a large component as the AGP could induce polar attachment would be that the AGP (or AGPcontaining complex) could bind to one or both bacterial poles, thereby promoting polar attachment to glass and other substrates. However, we cannot exclude the alternative model that attachment of the AGP to the sides of the bacteria could prevent the lateral attachment to glass that is normally observed in the absence of the AGP. In either scenario, the delay in attachment observed with the impL and type I protein secretion mutants could be explained by some change to the surface (e.g., an EPS), thereby reducing the binding of the AGP. The role for flagella (seen with the $f l i F$ and $f l g E$ mutants) could either be to help in the AGP binding or perhaps to enable the bacteria to enter into the hexagonal close packed arrays.

It is well established that rhizobia and agrobacteria attach in a polar manner to plant surfaces (Matthysse and Kijne 1998; Tomlinson and Fuqua 2009), although the reasons for attaching in a polar manner are not so clear. Possibly, this allows a more effective means of attachment that can be stabilized by polar structures and by the interactions between the bacteria that occur when they form a hexagonal close-packed array.

Our work does not necessarily demonstrate that the polar attachment factor is a single glycoprotein, because its high apparent molecular weight could indicate that it is a complex containing different components. Many AGP are heterogeneous with diverse glycosylation, and the protein component can constitute only a minor part. We were unable to identify a specific peptide using mass spectroscopy methods but this could be caused by glycosylation affecting the detection. Although more than 50 genes encoding AGP have been identified in Arabidopsis (Schultz et al. 2002), there are many other proteins with arabinogalactan-chains (Borner et al. 2003) and it is likely that pea has at least as many arabinogalactan glycosylated proteins. Rhizobia can form a biofilm on Arabidopsis roots (Santaella et al. 2008); a specific role for AGP has been proposed for bacterial attachment to root border-like cells (Vicre et al. 2005) and a specific AGP plays a role in attachment of agrobacteria to Arabidopsis roots (Gaspar et al. 2004). There are more than 50 predicted AGP in the Arabidopsis genome (Schultz et al. 2002). A mutation affecting one of these, AtAGP17, conferred resistance to Agrobacterium-mediated transformation (rat1) and reduced agrobacterial attachment to roots (Gaspar et al. 2004). We tested whether root exudate from the Arabidopsis ratl mutant was altered for induction of in vitro polar attachment by $R$. leguminosarum bv. viciae but detected no difference between the ratl mutant and the wild type. Although this AGP is unlikely to induce the observed polar attachment by $R$. leguminosarum bv. viciae, our observations would be consistent with one or more related AGP in root exudate promoting polar attachment.

\section{MATERIALS AND METHODS}

Bacterial strains, growth, and assays of polar attachment.

Bacterial strains and plasmids used in this study are listed in Table 2. Microbial growth conditions were as described previously (Williams et al. 2008). As described previously, (Russo et al. 2006), an inverted confocal laser-scanning microscope (Leica SP2) was used to monitor bacterial attachment to the base of growth chambers that have an optical glass base. The strains carried GFPuv expressed from pHC60 (Williams et al. 2008) and were grown in $400 \mu \mathrm{l}$ of Y-mannitol minimal medium in static cultures at $28^{\circ} \mathrm{C}$. Crude root exudates or purified fractions were filter sterilized $(0.22-\mu \mathrm{m}$ filter) before use and $40 \mu \mathrm{l}$ was usually added to the $400 \mu \mathrm{l}$ of Y medium in the assay chambers. In some experiments, the medium was buffered

Table 2. Stains and plasmids

\begin{tabular}{|c|c|c|}
\hline Rhizobium leguminosarum & Relevant characteristics $^{\mathbf{a}}$ & Source \\
\hline 3841 & bv. viciae, $\mathrm{Str}^{\mathrm{r}}$ & Brewin et al. 1980 \\
\hline $3841 \mathrm{rem}$ & 3841, rem $\Omega \mathrm{Km}^{\mathrm{r}}$ & Tambalo et al. $2010 \mathrm{~b}$ \\
\hline 3841 visN & $3841, v i s N \Omega S^{r}{ }^{r}$ & Tambalo et al. 2010b \\
\hline 3841 visR & 3841 visR $\Omega \mathrm{Km}^{\mathrm{r}}$ & Tambalo et al. $2010 \mathrm{~b}$ \\
\hline 8401 & R. leguminosarum lacking symbiosis plasmid & Lamb et al. 1982 \\
\hline A34 & 8401 carrying the bv. viciae symbiosis plasmid pRL1JI & Downie et al. 1985 \\
\hline A897 & 3841 virB6::Tn5 & Krehenbrink and Downie, 2008 \\
\hline A912 & 3841 prs $D:: \operatorname{Tn} 5\left(\mathrm{Gm}^{\mathrm{r}}\right)$, tobD $:: \operatorname{Tn} 5$, toaD $\Omega \mathrm{Sp}^{\mathrm{r}}$ & Krehenbrink and Downie, 2008 \\
\hline A1019 & 3841 aut $A:: \operatorname{Tn} 5$, aut $B:: \operatorname{Tn} 5\left(\mathrm{Gm}^{\mathrm{R}}\right)$, autC$C \Omega \mathrm{Sp}^{\mathrm{r}}$ & This work \\
\hline A1020 & 3841 exoY::Tn5 & Williams et al. 2008 \\
\hline A1045 & 3841 gms $A:: \operatorname{Tn} 5$ & Williams et al. 2008 \\
\hline A1056 & 3841 срав::Tn5 & This work \\
\hline A1060 & 3841 celA:: $\operatorname{Tn} 5$ & Williams et al. 2008 \\
\hline A1066 & 3841 flaB:: Tn5 & This work \\
\hline A1070 & 3841 flaA::Tn5 & This work \\
\hline A1073 & 3841 pss $A:: \operatorname{Tn} 5$ & Williams et al. 2008 \\
\hline A1090 & 3841 gelA::Tn5 & Williams et al. 2008 \\
\hline A1319 & $3841{\text { impL } L A p r^{r}}^{2}$ & This work \\
\hline A1414 & 3841 fliF $:: \operatorname{Tn} 5$ & This work \\
\hline A1415 & 3841 flgE:: Tn5 & This work \\
\hline LM300 & 3841 ache 1,2 & Miller et al. 2007 \\
\hline
\end{tabular}

${ }^{\text {a }} \mathrm{Str}^{\mathrm{r}}, \mathrm{Km}^{\mathrm{r}}, \mathrm{Sp}^{\mathrm{r}}, \mathrm{Gm}^{\mathrm{r}}$, and $\mathrm{Ap}^{\mathrm{r}}$ indicate resistant to streptomycin, kanamycin, spectinomycin, gentamicin, and ampicillin respectively. 
to $\mathrm{pH} 6.5$ or 7.5 using $20 \mathrm{mM}$ MOPS buffer. Data analysis was carried out with LCSLite confocal image software.

\section{Construction of $\boldsymbol{R}$. leguminosarum bv. viciae mutants.}

To make strain A1019 carrying mutations in each of the three autotransporter ( $a u t A, a u t B$, and $a u t C$ ) genes, the antibiotic kanamycin resistance genes in the mutants A1011 (autB::Tn5) and A1012 (autC::Tn5) (Krehenbrink and Downie 2008) were exchanged with gentamicin and spectinomycin resistance genes, respectively, using plasmids pJQ175 and pJQ173 as described (Quandt et al. 2004). The mutations were then sequentially transduced into strain A1010 (autA::Tn5) (Krehenbrink and Downie 2008), using phage RL38 as described previously (Buchanan-Wollaston 1979), selecting for gentamicin and spectinomycin resistance. Mutations in $c p a B$ (Krehenbrink and Downie 2008), exoY, gmsA, celA, pssA, gelA, flgE, fliF, flaA, and flaB were identified by using polymerase chain reaction (PCR) to screen a Tn5 mutant population using gene-specific primers and a Tn5-specific primer as described previously (Williams et al. 2008); the insertions in the genes were confirmed with the individual mutants by sequencing the PCR products. A1319 carrying an apramycinresistance cassette in the homologue (pRL120464) of impL encoding a component of a type VI secretion system (Bladergroen et al. 2003) was made using the Redirect system (Gust et al. 2003); initially, impL in the cosmid pIJ111334 was replaced with the apramycin resistance cassette in Escherichia coli to produce pIJ11137, which was then conjugated into $R$. leguminosarum bv. viciae 3841, selecting for apramycin resistance and screening for sensitivity to kanamycin to identify double recombination events. Resulting colonies were checked by DNA sequencing of PCR products generated by impL-specific primers and primers from the apramycin cassette.

\section{Preparation of root exudate.}

Sterile germinated pea (Pisum sativum 'Frisson') seedlings (Knight et al. 1986) with 1- to 2-cm roots were placed in sterilized glass jars $(15 \mathrm{~cm}$ high by $9 \mathrm{~cm}$ in diameter) containing glass beads $(6 \mathrm{~mm}$ in diameter; Atlas Ball and Bearings Co. Ltd., Walsall West Midlands, U.K.) and water (approximately $100 \mathrm{ml}$ ), such that the beads were approximately $6 \mathrm{~cm}$ deep and the water level was $1 \mathrm{~cm}$ below the top layer of the beads. The jars containing 10 to 12 pea seedlings were plugged with sterile foam bungs and the bottom $8 \mathrm{~cm}$ was wrapped in black plastic and incubated for 18 days at $22^{\circ} \mathrm{C}$ in a cycle of $18 \mathrm{~h}$ of light and $6 \mathrm{~h}$ of darkness in a plant growth cabinet. The pea plants were removed and the remaining liquid (referred to as root exudate) was poured off (usually 60 to $80 \mathrm{ml}$ ) and checked for sterility by plating $100 \mu \mathrm{l}$ of the liquid on a tryptone yeast plate. Uncontaminated exudate was centrifuged $(9,000 \times \mathrm{g}$ for $30 \mathrm{~min})$, passed through a sterile $0.22-\mu \mathrm{m}$ filter, and stored at $4{ }^{\circ} \mathrm{C}$. Root exudates of wheat, A. thaliana (Col-0), L. japonicus (Gifu B-129), and M. truncatula (Jemalong A17) were produced by growing sterile seedlings on water agar until the roots were approximately 1 to $2 \mathrm{~cm}$ long. The seedlings were then transferred to modified Fahraeus slides containing approximately $1 \mathrm{ml}$ sterile of $\mathrm{H}_{2} \mathrm{O}$. For each preparation, approximately three to five slides were used, and these were placed in petri dishes containing moist filter paper to prevent drying and incubated in a growth cabinet for 3 to 5 days, after which the remaining liquid was removed from the roots and passed through a sterile $0.22-\mu \mathrm{m}$ filter.

\section{Treatment with proteases and viscozyme.}

ProteinaseK, pronaseE, or ViscozymeL (Sigma-Aldrich, St. Louis) were made up at $1 \mathrm{mg} / \mathrm{ml}$ in $25 \mathrm{mM}$ potassium phosphate buffer $(\mathrm{pH} 7.5)$ and added to a final concentration of 0.1 $\mathrm{mg} / \mathrm{ml}$ to crude pea root exudate. The mix was incubated for $1 \mathrm{~h}$ at $37^{\circ} \mathrm{C}$, then heated at $75^{\circ} \mathrm{C}$ for $15 \mathrm{~min}$ to denature enzyme activity. As a control for heat denaturation, the enzymes were heat treated before use and then added to root exudate as above; this inactivated the enzymes based on the observation that normal polar attachment was induced after the root exudate was incubated with the heat-treated enzymes.

\section{Purification and analysis of the polar attachment factor.}

Filtered root exudate (2 liters) was passed through a column (bed volume: 6 by $2 \mathrm{~cm}$ in diameter) containing the cation exchange resin CNP-105 (Fluka, Buchs Switzerland). The flowthrough was then applied to a DEAE-sephadex column (bed volume: 6 by $2 \mathrm{~cm}$ in diameter) and the resin was washed with $50 \mathrm{ml}$ of water and then eluted with a step gradient using 30 $\mathrm{ml}$ of $0.1 \mathrm{M} \mathrm{NaCl}$ and then $30 \mathrm{ml}$ of $0.3 \mathrm{M} \mathrm{NaCl}$. This second eluate was diluted threefold with water and then loaded onto a C18 reverse phase column (Sep-Pak; Waters, Milford, MA, U.S.A.), which was washed with $20 \mathrm{ml}$ of water. This column was sequentially eluted with $10 \mathrm{ml}$ each of 10,30 , and $50 \%$ methanol in water. The first and last elutions released very little polar attachment activity, with most of the bound activity eluted with $30 \%$ methanol. To assay the activity, the eluates were vacuum centrifuged to decrease the volume to $500 \mu \mathrm{l}$ and bioassayed. The active fraction from the $30 \%$ methanol eluate was separated using FPLC on a Superdex 200 10/300 GL column using a flow rate of $0.5 \mathrm{ml} / \mathrm{min}$ of $20 \mathrm{mM}$ Tris- $\mathrm{HCl}$ buffer, $\mathrm{pH}$ 8.0. The column was eluted until the eluate had an optical density close to 0 at $280 \mathrm{~nm}$ and 1-ml fractions were collected and assayed for polar attachment activity. The three fractions with activity were pooled and desalted, using a PD10 column (GE Healthcare, Piscataway, NJ, U.S.A.), and were concentrated approximately 40 -fold, using a vacuum centrifuge. This fraction was used for the carbohydrate analysis, the radial gel diffusion assay with Yariv reagent, and the immunoassays with monoclonal antibodies.

Sugar analysis of the active purified fraction was done by combined gas chromatography/mass spectrometry of the perO-trimethylsilyl derivatives at the Complex Carbohydrate Research Center, (Athens, GA, U.S.A.). Radial gel diffusion assays with $\beta$-glucosyl Yariv reagent were done as described previously using a $1 \%$ agarose gel containing $0.15 \mathrm{M} \mathrm{NaCl}, \mathrm{NaN}_{3}$ at $0.2 \mathrm{mg} / \mathrm{ml}$, and $\beta$-glucosyl Yariv reagent at $0.03 \mathrm{mg} / \mathrm{ml}$; in this assay, the reagent formed a ring of brown precipitate with AGP diffusing from the well (Van Holst and Clarke 1985). Aliquots of the purified fraction were pipetted into the wells and the gel was incubated overnight at room temperature in a box with high relative humidity to avoid drying of the gel. Gum Arabic was used as a positive control.

Monoclonal antibodies were used in dot immunoassays as described (Smallwood et al. 1996). Briefly, 1- $\mu$ l aliquots of purified polar attachment fraction were blotted onto a nitrocellulose membrane and then air dried at root temperature for $1 \mathrm{~h}$. The membrane was then treated for $1 \mathrm{~h}$ at room temperature with $5 \%$ (wt/vol) nonfat milk in phosphate-buffered saline (PBS). The filters were then incubated for $1.5 \mathrm{~h}$ at root temperature in fresh buffer containing a 1:50 (vol/vol) dilution of the monoclonal antibodies JIM13, LM2, and MAC265. The filters were then washed three times for 5 min with PBS and then incubated for $90 \mathrm{~min}$ at room temperature with antirat immunoglobulin $\mathrm{G}$ conjugated with alkaline phosphatase (Sigma-Aldrich) diluted 1:1000 ( $\mathrm{vol} / \mathrm{vol})$ in PBS. After another three washes, the blot was developed at room temperature with 5-bromo-4-chloro-3-indolyl phosphate and nitroblue tetrazolium (Sigmafast; Sigma-Aldrich). LM2 and JIM13 recognize AGP (Knox et al. 1991; Samaj et al. 2000) and the epitope recognized by JIM13 has been identified as $\beta$-D-GlcA- 
(1,3)- $\alpha$-D-GalA-(1,2)- $\alpha$-L-Rha. MAC265 recognizes extensinAGP (Rathbun et al. 2002).

\section{ACKNOWLEDGMENTS}

We thank M. Hynes and D. Tambalo for generously providing strains as indicated in Table 1; A. Swiderska for making strains A1066 and A1070; M. Krehenbrink for making strain A1019 and for helpful suggestions; G Calder and A. Johnston for their generous help with the use of and access to confocal microscopy; L. Hill and J. Fan for advice and suggestions for the purification of the polar attachment factor; P. Dupree, S. Fry, P. Knox, and N. Brewin for advice on dealing with AGP; C. Schultz for sending seed of the rat1 mutant; the CCRC for their sugar analysis; and members of our and P. Poole's research groups for help, suggestions, and encouragement. This work was supported by Biotechnology and Biological Sciences Research Council grant E017045/1, a grant in aid to the John Innes Centre and the John Innes Foundation.

\section{LITERATURE CITED}

Aschtgen, M. S., Gavioli, M., Dessen, A., Lloubes, R., and Cascales, E. 2010. The SciZ protein anchors the enteroaggregative Escherichia coli Type VI secretion system to the cell wall. Mol. Microbiol. 75:886-899.

Ausmees, N., Jacobsson, K., and Lindberg, M. 2001. A unipolarly located, cell-surface-associated agglutinin, RapA, belongs to a family of Rhizobium-adhering proteins (Rap) in Rhizobium leguminosarum bv. trifolii. Microbiology 147:549-559.

Bladergroen, M. R., Badelt, K., and Spaink, H. P. 2003. Infection-blocking genes of a symbiotic Rhizobium leguminosarum strain that are involved in temperature-dependent protein secretion. Mol. Plant-Microbe Interact. 16:53-64.

Borner, G. H. H., Lilley, K. S., Stevens, T. J., and Dupree, P. 2003. Identification of glycosylphosphatidylinositol-anchored proteins in Arabidopsis. A proteomic and genomic analysis. Plant Physiol. 132:568-577.

Brewin, N. J., Beringer, J. E., and Johnston, A. W. B. 1980. Plasmid-mediated transfer of host range specificity between two strains of Rhizobium leguminosarum. J. Gen. Microbiol. 120:413-420.

Buchanan-Wollaston, A. V. 1979. Generalised transduction in Rhizobium leguminosarum. J. Gen. Microbiol. 112:135-142.

Chesnokova, O., Coutinho, J. B., Khan, I. H., Mikhail, M. S., and Kado, C. I. 1997. Characterization of flagella genes of Agrobacterium tumefaciens, and the effect of a bald strain on virulence. Mol. Microbiol. 23:579-590.

Chevance, F. F. V., and Hughes, K. T. 2008. Coordinating assembly of a bacterial macromolecular machine. Nat. Rev. Microbiol. 6:455-465.

Danhorn, T., and Fuqua, C. 2007. Biofilm formation by plant-associated bacteria. Annu. Rev. Microbiol. 61:401-422.

Downie, J. A. 2010. The roles of extracellular proteins, polysaccharides and signals in the interactions of rhizobia with legume roots. FEMS (Fed. Eur. Microbiol. Soc.) Microbiol. Rev. 34:150-170.

Downie, J. A., Knight, C. D., Johnston, A. W. B., and Rossen, L. 1985. Identification of genes and gene products involved in the nodulation of peas by Rhizobium leguminosarum. Mol. Gen. Genet. 198:255-262.

Estabrook, E. M., and Yoder, J. I. 1998. Plant-plant communications: rhizosphere signaling between parasitic angiosperms and their hosts. Plant Physiol. 116:1-7.

Faure, D., Vereecke, D., and Leveau, J. H. J. 2009. Molecular communication in the rhizosphere. Plant Soil 321:279-303.

Fujishige, N. A., Kapadia, N. N., De Hoff, P. L., and Hirsch, A. M. 2006. Investigations of Rhizobium biofilm formation. FEMS (Fed. Eur. Microbiol. Soc.) Microbiol. Ecol. 56:195-206.

Fujishige, N. A., Lum, M. R., De Hoff, P. L., Whitelegge, J. P., Faull, K. F., and Hirsch, A. M. 2008. Rhizobium common nod genes are required for biofilm formation. Mol. Microbiol. 67:504-515.

Gao, M., Teplitski, M., Robinson, J. B., and Bauer, W. D. 2003. Production of substances by Medicago truncatula that affect bacterial quorum sensing. Mol. Plant Microbe Interact. 16:827-834.

Gaspar, Y. M., Nam, J., Schultz, C. J., Lee, L. Y., Gilson, P. R., Gelvin, S. B., and Bacic, A. 2004. Characterization of the Arabidopsis lysine-rich arabinogalactan-protein AtAGP17 mutant (rat1) that results in a decreased efficiency of Agrobacterium transformation. Plant Physiol. 135:2162-2171.

Gust, B., Challis, G. L., Fowler, K., Kieser, T., and Chater, K. F. 2003. PCR-targeted Streptomyces gene replacement identifies a protein domain needed for biosynthesis of the sesquiterpene soil odor geosmin. Proc. Natl. Acad. Sci. U.S.A. 100:1541-1546.

Harborne, J. B., and Baxter, H. 1999. Phytochemical Dictionary: A Handbook of Bioactive Compounds from Plants. Taylor and Francis, London.
Jakubowski, S. J., Krishnamoorthy, V., and Christie, P. J. 2003. Agrobacterium tumefaciens $\mathrm{VirB} 6$ protein participates in formation of VirB7 and VirB9 complexes required for type IV secretion. J. Bacteriol. 185:28672878.

Keshavan, N. D., Chowdhary, P. K., Haines, D. C., and Gonzalez, J. E. 2005. L-Canavanine made by Medicago sativa interferes with quorum sensing in Sinorhizobium meliloti. J. Bacteriol. 187:8427-8436.

Knee, E. M., Gong, F. C., Gao, M. S., Teplitski, M., Jones, A. R., Foxworthy, A., Mort, A. J., and Bauer, W. D. 2001. Root mucilage from pea and its utilization by rhizosphere bacteria as a sole carbon source. Mol. PlantMicrobe Interact. 14:775-784.

Knight, C. D., Rossen, L., Robertson, J. G., Wells, B., and Downie, J. A. 1986. Nodulation inhibition by Rhizobium leguminosarum multicopy nodABC genes and analysis of early stages of plant infection. J. Bacteriol. 166:552-558.

Knox, J. P., Linstead, P. J., Peart, J., Cooper, C., and Roberts, K. 1991. Developmentally regulated epitopes of cell-surface arabinogalactan proteins and their relation to root-tissue pattern formation. Plant J. 1:317326.

Krehenbrink, M., and Downie, J. A. 2008. Identification of protein secretion systems and novel secreted proteins in Rhizobium leguminosarum bv. viciae. BMC Genomics 9:55.

Lamb, J. W., Hombrecher, G., and Johnston, A. W. B. 1982. Plasmiddetermined nodulation and nitrogen-fixation abilities in Rhizobium phaseoli. Mol. Gen. Genet. 186:449-452.

Laus, M. C., van Brussel, A. A. N., and Kijne, J. W. 2005. Exopolysaccharide structure is not a determinant of host-plant specificity in nodulation of Vicia sativa roots. Mol. Plant-Microbe Interact. 18:1123-1129.

Laus, M. C., Logman, T. J., Lamers, G. E., Van Brussel, A. A. N., Carlson, R. W., and Kijne, J. W. 2006. A novel polar surface polysaccharide from Rhizobium leguminosarum binds host plant lectin. Mol. Microbiol. 59:1704-1713.

Mark, G. L., Dow, J. M., Kiely, P. D., Higgins, H., Haynes, J., Baysse, C., Abbas, A., Foley, T., Franks, A., Morrissey, J., and O'Gara, F. 2005 Transcriptome profiling of bacterial responses to root exudates identifies genes involved in microbe-plant interactions. Proc. Natl. Acad. Sci. U.S.A. 102:17454-17459.

Matilla, M. A., Espinosa-Urgel, M., Rodriguez-Herva, J. J., Ramos, J. L., and Ramos-Gonzalez, M. I. 2007. Genomic analysis reveals the major driving forces of bacterial life in the rhizosphere. Genome Biol. $8: R 179$

Matthysse, A. G., and Kijne, J. W. 1998. Attachment of Rhizobiaceae to plant cells. Pages 135-249 in: The Rhizobiaceae. H. P Spaink, A. Kondorosi, and P .J. J. Hooykaas, eds. Kluwer Academic, Dordrecht, The Netherlands.

Merritt, P. M., Danhorn, T., and Fuqua, C. 2007. Motility and chemotaxis in Agrobacterium tumefaciens surface attachment and biofilm formation. J. Bacteriol. 189:8005-8014.

Miller, L. D., Yost, C. K., Hynes, M. F., and Alexandre, G. 2007. The major chemotaxis gene cluster of Rhizobium leguminosarum bv. viciae is essential for competitive nodulation. Mol. Microbiol. 63:348-362.

Quandt, J., Clark, R. G., Venter, A. P., Clark, S. R. D., Twelker, S., and Hynes, M. F. 2004. Modified RN and Tn5-Mob derivatives for facilitated manipulation of large plasmids in gram-negative bacteria. Plasmid 52:1-12.

Rathbun, E. A., Naldrett, M. J., and Brewin, N. J. 2002. Identification of a family of extensin-like glycoproteins in the lumen of Rhizobiuminduced infection threads in pea root nodules. Mol. Plant-Microbe Interact. 15:350-359.

Russo, D. M., Williams, A., Edwards, A., Posadas, D. M., Finnie, C., Dankert, M., Downie, J. A., and Zorreguieta, A. 2006. Proteins exported via the PrsD-PrsE type I secretion system and the acidic exopolysaccharide are involved in biofilm formation by Rhizobium leguminosarum. J. Bacteriol. 188:4474-4486.

Samaj, J., Samajofi, O., Peters, M., Balu-ka, E., Lichtscheidl, I., Knox, J. P., and Volkmann, D. 2000. Immunolocalizaion of LM2 arabinogalactan protein epitope associated with endomembranes of plant cells. Protoplasma 212:1186-1196.

Santaella, C., Schue, M., Berge, O., Heulin, T., and Achouak, W. 2008. The exopolysaccharide of Rhizobium sp. YAS34 is not necessary for biofilm formation on Arabidopsis thaliana and Brassica napus roots but contributes to root colonization. Environ. Microbiol. 10:2150-2163.

Schultz, C. J., Rumsewicz, M. P., Johnson, K. L., Jones, B. J., Gaspar, Y M., and Bacic, A. 2002. Using genomic resources to guide research directions. The arabinogalactan protein gene family as a test case. Plant Physiol. 129:1448-1463.

Schwarz, S., Hood, R. D., and Mougous, J. D. 2010. What is type VI secretion doing in all those bugs? Trends Microbiol. 18:531-537.

Smallwood, M., Yates, E. A., Willats, W. G. T., Martin, H., and Knox, J. P. 1996. Immunochemical comparison of membrane-associated and se- 
creted arabinogalactan-proteins in rice and carrot. Planta 198:452-459.

Smit, G., Kijne, J. W., and Lugtenberg, B. J. J. 1986. Correlation between extracellular fibrils and attachment of Rhizobium leguminosarum to pea root hair tips. J. Bacteriol. 168:821-827.

Smit, G., Logman, T. J. J., Boerrigter, M., Kijne, J. W., and Lugtenberg, B. J. J. 1989. Purification and partial characterization of the Rhizobium leguminosarum biovar viciae $\mathrm{Ca}^{2+}$-dependent adhesin, which mediates the 1st step in attachment of cells of the family Rhizobiaceae to plantroot hair tips. J. Bacteriol. 171:4054-4062.

Smit, G., Swart, S., Lugtenberg, B. J. J., and Kijne, J. W. 1992. Molecular mechanisms of attachment of Rhizobium bacteria to plant roots. Mol. Microbiol. 6:2897-2903.

Swart, S., Lugtenberg, B. J. J., Smit, G., and Kijne, J. W. 1994. Rhicadhesin mediated attachment and virulence of an Agrobacterium tumefaciens $\operatorname{chv} B$ mutant can be restored by growth in a highly osmotic medium. J. Bacteriol. 176:3816-3819.

Tambalo, D. D., Bustard, D. E., Del Bel, K. L., Koval, S. F., Khan, M. F., and Hynes, M. F. 2010a. Characterization and functional analysis of seven flagellin genes in Rhizobium leguminosarum bv. viciae. Characterization of $R$. leguminosarum flagellins. BMC Microbiol. 10:219.

Tambalo, D. D., Del Bel, K. L., Bustard, D. E., Greenwood, P. R. Steedman, A. E., and Hynes, M. F. 2010b. Regulation of flagellar, motility and chemotaxis genes in Rhizobium leguminosarum by the VisN/R-Rem cascade. Microbiology 156:1673-1685.
Tomlinson, A. D., and Fuqua, C. 2009. Mechanisms and regulation of polar surface attachment in Agrobacterium tumefaciens. Curr. Opin. Microbiol. 12:708-714.

Van Holst, G. J., and Clarke, A. E. 1985. Quantification of arabinogalactan-protein in plant extracts by single radial gel diffusion. Anal. Biochem. 148:446-450.

Vicre, M., Santaella, C., Blanchet, S., Gateau, A., and Driouich, A. 2005. Root border-like cells of Arabidopsis. Microscopical characterization and role in the interaction with rhizobacteria. Plant Physiol. 138:9981008.

Williams, A., Wilkinson, A., Krehenbrink, M., Russo, D.M., Zorreguieta, A., and Downie, J.A. 2008. Glucomannan-mediated attachment of $R h i$ zobium leguminosarum to pea root hairs is required for competitive nodule infection. J. Bacteriol. 190:4706-4715.

Yates, E. A., Valdor, J. F., Haslam, S. M., Morris, H. R., Dell, A., Mackie, W., and Knox, J. P. 1996. Characterization of carbohydrate structural features recognized by anti-arabinogalactan-protein monoclonal antibodies. Glycobiology 6:131-139.

\section{AUTHOR-RECOMMENDED INTERNET RESOURCE}

University of Leeds, Paul Knox Cell Wall Lab webpage: www.personal.leeds.ac.uk/ bmbjpk/protocols.htm 